\title{
Disponibilidade de sódio em solo com capim tifton e aplicação de percolado de resíduo sólido ${ }^{1}$
}

\author{
Denise de F. Silva2 ${ }^{2}$ Antonio T. de Matos ${ }^{2}, 0$ dilon G. Pereira 3 , Paulo R. Cecon ${ }^{4} \&$ Débora A. Moreira ${ }^{2}$
}

\begin{abstract}
RESUMO
Avaliaram-se, com a realização deste trabalho, as al terações na concentração e na saturação do complexo de troca com sódio, em solo cultivado com capim-tifton 85 submetido à aplicação de percolado de resíduo sólido urbano (RSU) em diferentes taxas. Para o desenvolvimento desta pesquisa um reservatório de $5.000 \mathrm{~L}$ foi prenchido com RSU novo, visando-se à produção de percolado. 0 percolado foi aplicado nas taxas de 0 (testemunha), 250, 500,750, $1000 \mathrm{~kg} \mathrm{ha}^{-1} \mathrm{~d}^{-1}$ de DBO ${ }_{5}$. No tratamento testemunha, não receptor do percolado, aplicou-se água da rede de abastecimento público na mesma lâmina definida para aplicação no tratamento $500 \mathrm{~kg} \mathrm{ha}^{-1} \mathrm{~d}^{-1}$ de DBO ${ }_{5}$. A aplicação da água e do percolado foi feita diariamente, durante oito meses. A aplicação de percolado de RSU proporcionou acúmulo de sódio em todas as camadas avaliadas do solo porém não causou prejuízo à sua qualidade. Taxas de aplicação inferiores a $1000 \mathrm{~kg} \mathrm{ha}^{-1} \mathrm{~d}^{-1}$ de DBO ${ }_{5}$ de percolado de RSU não proporcionaram problemas ao solo durante o período experimental e, portanto, podem ser utilizadas para disposição dessas águas residuárias. Verificou-se, ao final do período de realização do experimento, que os valores de percentagem de saturação de sódio (PST) permaneceram abaixo do limite de $15 \%$ porém se espera, em uma estimativa de aplicação mais prolongada, a superação desses limites na camada mais superficial do solo $(0$ a 0,10 m) após 1,2 anos de aplicação do percolado de RSU.
\end{abstract}

Palavras-chave: chorume, aterro sanitário, fertirrigação

\section{Sodium availability in a soil with tifton grass and application of solid waste leachate}

\begin{abstract}
Changes were evaluated in concentration and saturation of exchangeable sodium of a soil cropped with tifton-85 grass, submitted to different rates of municipal solid waste leachate (MSW). For this research, a $5000 \mathrm{~L}$ reservoir was filled with fresh MSW in order to produce leachate. Leachate rates of 0 (control), 250, 500, 750 and $1000 \mathrm{~kg} \mathrm{ha}^{-1} \mathrm{~d}^{-1}$ of BOD 5 were applied to the field. In the control treatment, which did not receive any leachate, potable water from the municipal supply network were applied at the same depth as for the $500 \mathrm{~kg} \mathrm{ha}^{-1} \mathrm{~d}^{-1}$ of $\mathrm{BOD}_{5}$. W ater and leachate was applied to tifton grass daily during an eight month period. The applied MSW leachate provided sodium accumulation in all soil profile layers, however, without any damage to quality. MSW doses of less than $1000 \mathrm{~kg} \mathrm{ha}^{-1} \mathrm{~d}^{-1}$ of $B O D_{5}$ caused no problems to soil during the research period and, therefore, it can be used to dispose such effluent At the end of trial, one could note that exchangeable sodium percentage (PST) remained lower than the $15 \%$ limit. However, for longer applications, one would expect the limit to be exceeded in the superficial soil layer $(0$ to $0.10 \mathrm{~m}$ ) after 1.2 years of M SW leachate application.
\end{abstract}

Key words: landfill leachates, sanitary landfill, fertirrigation

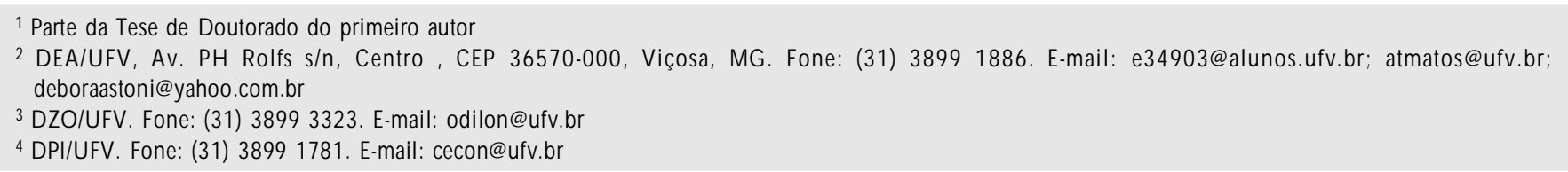




\section{INTRODUÇÃO}

A problemática dos resíduos sólidos urbanos (RSU) abrange, nesse meio, aspectos relacionados à sua origem e forma de produção, destacando-se os riscos de comprometimento ambiental, sobretudo no que se refere à poluição do solo, do ar e dos recursos hídricos, quando dispostos de forma inadequada. O não tratamento dessa massa de resíduos pode contribuir significativamente para a degradação da biosfera, em detrimento da qualidade de vida no planeta.

Percolado é todo líquido que passa através de um meio poroso. No caso de aterros sanitários, é a mistura constituída de chorume e água de infiltração (Marnie et al., 2005), que é dependente do índice pluviométrico local, do escoamento superficial, da possível intrusão de águas subterrâneas nas células e do volume de resíduos orgânicos presentes no aterro.

A fonte de água de percolação pode ser a precipitação, irrigação, águas subterrâneas ou percolados recirculados através do aterro (Qian et al., 2002). Os mesmos autores relataram uma produção de percolados entre 2 e $3 \mathrm{~mm} \mathrm{~d}^{-1}$ em aterros sanitários de Nova York. Carvalho et al. (2006) obtiveram lâminas de percolado de $5 \mathrm{~mm} \mathrm{~d}^{-1}$ em colunas de RSU recémcoletado, contendo camada de $0,30 \mathrm{~m}$ de resíduo da construção civil (RCC) na sua base, enquanto naquela que não a continha a lâmina média obtida foi de $3,9 \mathrm{~mm} \mathrm{~d}^{-1}$.

A poluição do solo e de águas superficiais e subterrâneas, provocada pelo percolado de RSU, devido a tratamento ou manejo inadequados, passou a ser motivo de estudos em todo o mundo, principalmente nos países industrializados dado ao reconhecido potencial poluidor e ao grande volume gerado diariamente (Aluko \& Sridhar, 2005).

No Brasil, quando o tratamento do percolado é realizado in situ, frequentemente se utilizam lagoas de estabilização, sistemas que requerem grandes áreas, muitas vezes pouco disponíveis em grandes centros urbanos. Além disso, a eficiência relativamente baixa do sistema convencional de tratamento (lagoas anaeróbia seguida de facultativas) tem levado técnicos e pesquisadores a procurarem alternativas técnicas que possibilitem o tratamento/disposição final com menor custo econômico e ambiental (Carvalho et al., 2006).

Segundo a CETESB (1995), um método tecnicamente viável para o condicionamento de percolado é a adoção de um sistema que permita sua recirculação no próprio aterro sanitário. A recirculação do percolado no interior do aterro sanitário, realizada de maneira que ele possa percolar através da massa de sólidos disposta em camadas, é uma técnica atual e bastante inovadora no tratamento de líquido poluidor (IPT/ CEMPRE, 2000).

Carvalho et al. (2006), procedendo à recirculação de percolado em colunas de RSU de diferentes idades, contendo ou não uma camada de $0,30 \mathrm{~m}$ de resíduo de construção civil em sua base, concluíram que, quando a recirculação de percolado foi feita em colunas formadas por RSU maduro (3 anos) e velho (13 anos), houve grande remoção de Demanda Bioquímica de Oxigênio (DBO), Demanda Química de Oxigênio (DQO), Sólido Suspensão (SS) e nitrogênio total dessa água residuária. De acordo com os resultados obtidos nesta pes- quisa concluiu-se que a recirculação pode ser considerada técnica promissora, como método de tratamento do percolado somente se a aplicação for feita em células de RSU com idade superior a 3 anos. Em vista disso, entende-se que em aterros sanitários recém-instalados seria necessária a disponibilização de áreas de aplicação temporária do percolado no solo, até que o aterro disponha de células contendo RSU maduro.

O percolado proveniente de aterros sanitários apresenta alta variabilidade composicional, destacando-se a presença de nutrientes importantes para agricultura, como o nitrogênio, fósforo, potássio, alguns micronutrientes, além de matéria orgânica, atribuindo-lhe elevado potencial para aproveitamento agrícola (Matos et al., 2008).

O sódio, presente em concentrações relativamente altas no percolado, por ser um cátion de alta solubilidade, pode proporcionar aumento na condutividade elétrica e provocar diminuição no potencial osmótico do solo, distúrbios e comprometimento do desenvolvimento das plantas A presença de sódio na água de irrigação sob determinadas condições pode provocar decréscimo na permeabilidade do solo; entretanto, por se tratar de um cátion muito móvel pode, em regiões de altos índices pluviométricos, se movimentar em direção às águas subterrâneas, contaminando-as.

Por se tratar de um elemento químico abundante na natureza, o sódio pode ser encontrado disperso no meio sólido e líquido, porém está em alta concentração em algumas rochas como no mineral halita e na água de mar. Como cátion monovalente $\left(\mathrm{Na}^{+}\right)$, pode ser adsorvido aos colóides de solo e, quando em elevadas concentrações, é capaz de deslocar o $\mathrm{Ca}^{2+}$ e o $\mathrm{K}^{+}$desse complexo de troca, condição passível de afetar, em determinadas situações, a estrutura do solo (Oliveira et al., 2002).

Realizou-se este trabalho com o objetivo de que fossem avaliadas as alterações na concentração trocável e na saturação do complexo de troca com sódio, em solo cultivado com capim-tifton 85 submetido à aplicação de percolado de resíduo sólido urbano (RSU) em diferentes taxas.

\section{MATERIAL E MÉTODOS}

O experimento foi conduzido na Área Experimental de Tratamento de Resíduos Urbanos do Departamento de Engenharia Agrícola, na Universidade Federal de Viçosa, Viçosa, MG.

Para o desenvolvimento desta pesquisa um reservatório de 5.000 L foi prenchido com RSU novo, visando-se à produção de percolado. $\mathrm{O}$ percolado produzido neste reservatório era conduzido para um reservatório de $500 \mathrm{~L}$, de onde era, então, recalcado para outro reservatório de igual volume, localizado próximo à área experimental em que era feita a aplicação do percolado, conforme apresentado na (Figura 1). O solo da área experimental, segundo critérios estabelecidos pela Sociedade Brasileira de Ciência do Solo - SBCS, foi classificado como Cambissolo Háplico Tb distrófico latossólico (Vieira, 2003).

Em razão da grande declividade na área de cultivo do capim, foram construídos quatro patamares, em curva de nível 


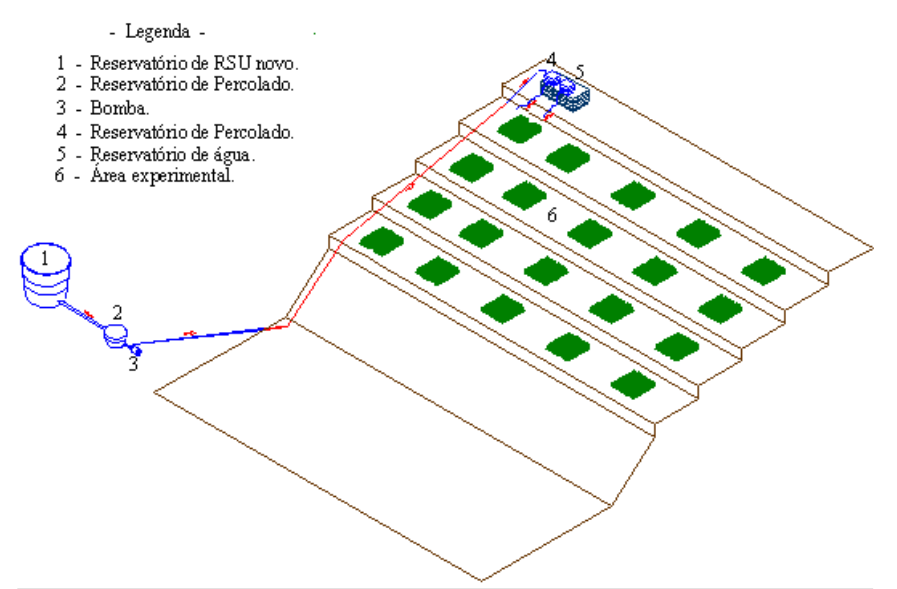

Figura 1. Esquema de produção, recalque e distribuição do percolado nos reservatórios e parcelas experimentais

(Figura 1) e delimitadas 20 parcelas de $4 \mathrm{~m}^{2}(2 \times 2 \mathrm{~m})$ cada uma, além de instaladas cinco parcelas em cada patamar.

Para preenchimento do reservatório de produção de percolado utilizou-se o RSU contido em dois caminhões de coleta efetuada na cidade de Viçosa, MG. A composição gravimétrica do RSU foi feita por quarteamento, despejando-se os resíduos sobre uma lona plástica e formando uma única pilha. O material foi espalhado e homogeneizado e, em seguida, quarteado. O componente de maior percentual no RSU foi a matéria orgânica $(56,4 \%)$, seguida de papel/papelão $(6,3 \%)$ e plástico fino $(7,3 \%)$, constituintes que representaram 70,0\% da massa total, valores semelhantes aos obtidos por Carvalho et al. (2006), em RSU coletado na mesma cidade.

Foram realizadas, durante o período experimental, seis coletas de amostra do percolado nas quais foram medidos o $\mathrm{pH}$ e a $\mathrm{CE}$ e quantificadas as concentrações totais de $\mathrm{DBO}_{5}, \mathrm{DQO}$, $\mathrm{P}, \mathrm{K}, \mathrm{Na}, \mathrm{Ca}, \mathrm{Mg}, \mathrm{N}, \mathrm{N}_{-} \mathrm{NH}_{4}{ }^{+}, \mathrm{N}_{-} \mathrm{NO}_{3}{ }^{-}, \mathrm{Cu}, \mathrm{Zn}, \mathrm{Cr}, \mathrm{Ni}, \mathrm{Mn}$ e Fe e, com base nos valores obtidos para $\mathrm{Na}, \mathrm{Ca}$ e $\mathrm{Mg}$, calculada a Razão de Adsorção de Sódio (RAS). A demanda bioquímica de oxigênio $\left(\mathrm{DBO}_{5}\right)$ e a demanda química de oxigênio (DQO) foram quantificadas seguindo-se metodologia recomendada em APHA (2005), sendo a determinação da $\mathrm{DBO}_{5}$ feita por quantificação de oxigênio dissolvido pelo método iodométrico e a da DQO pelo método do refluxo aberto. O nitrogênio total foi quantificado segundo o método Kjeldahl. Para quantificação da concentração de $\mathrm{N}-\mathrm{NH}_{4}{ }^{+}$, utilizou-se o método descrito por Kempers \& Zweers (1986). As análises de nitrato foram realizadas de acordo com o método descrito por Yang et al. (1998), fundamentadas no método colorimétrico. Após digestão nítrico-perclórico das amostras fez-se a quantificação da concentração de fósforo utilizando-se o método colorimétrico (EMBRAPA, 1997); a do potássio e do sódio, por fotometria de chama e a do cálcio e magnésio, por titulometria (APHA, 2005; EMBRAPA, 1997). Obtiveram-se o cobre, zinco, crômio, níquel, manganês e ferro, por espectrofotometria de absorção atômica. Os resultados obtidos estão apresentados na Tabela 1.

Fez-se, para avaliação das condições iniciais do solo, uma amostragem preliminar antes de se realizar o plantio e a aplicação do percolado de RSU, tendo-se colhido amostras simples nas profundidades de 0 a 0,$10 ; 0,10$ a 0,$20 ; 0,20$ a 0,30 ;
Tabela 1. Composição química do percolado de RSU coletado durante 0 período experimental

\begin{tabular}{|c|c|c|}
\hline \multicolumn{2}{|c|}{ Características } & Faixa de variação \\
\hline $\mathrm{pH}$ & - & $5,68-7,70$ \\
\hline CE & $\mathrm{mS} \mathrm{cm} \mathrm{cm}^{-1}$ & $12,31-19,37$ \\
\hline $\mathrm{DBO}_{5}$ & $\mathrm{mg} \mathrm{L}^{-1}$ & $5.363-31.598$ \\
\hline DQO & $\mathrm{mg} \mathrm{L}^{-1}$ & $10.726-63.196$ \\
\hline $\mathrm{N}$ & $\mathrm{mg} \mathrm{L}^{-1}$ & $124,5-1.576,0$ \\
\hline $\mathrm{P}$ & $\mathrm{mg} \mathrm{L}^{-1}$ & $41,3-108,5$ \\
\hline $\mathrm{K}^{+}$ & $\mathrm{mg} \mathrm{L}^{-1}$ & $106,3-3.663,5$ \\
\hline $\mathrm{Na}^{+}$ & $\mathrm{mg} \mathrm{L}^{-1}$ & $99,2-3.588,8$ \\
\hline $\mathrm{Ca}^{2+}$ & $\mathrm{mg} \mathrm{L}^{-1}$ & $78,4-1.267,3$ \\
\hline $\mathrm{Mg}^{2+}$ & $\mathrm{mg} \mathrm{L}^{-1}$ & $69,5-9.541,7$ \\
\hline RAS & $\left(\mathrm{mmol} \mathrm{L}^{-1}\right)^{0,5}$ & $2,8-10,4$ \\
\hline $\mathrm{Zn}$ & $m g L^{-1}$ & $0,0-8,3$ \\
\hline $\mathrm{Fe}$ & $\mathrm{mg} \mathrm{L}^{-1}$ & $83,4-981,3$ \\
\hline $\mathrm{Cu}$ & $\mathrm{mg} \mathrm{L}^{-1}$ & $0,0-16,3$ \\
\hline $\mathrm{Mn}$ & $\mathrm{mg} \mathrm{L}^{-1}$ & $2,6-33,1$ \\
\hline $\mathrm{Cr}$ & $\mathrm{mg} \mathrm{L}^{-1}$ & $0,0-2,0$ \\
\hline $\mathrm{Ni}$ & $\mathrm{mg} \mathrm{L}^{-1}$ & $0,0-1,6$ \\
\hline $\mathrm{N}-\mathrm{NH}_{4}^{+}$ & $\mathrm{mg} \mathrm{L}^{-1}$ & $71,7-286,7$ \\
\hline $\mathrm{N}-\mathrm{NO}_{3}^{-}$ & $\mathrm{mg} \mathrm{L}^{-1}$ & $3,2-8,3$ \\
\hline
\end{tabular}

0,30 a 0,$40 ;$ e 0,60 a $0,70 \mathrm{~m}$, com auxílio de um trado tipo holandês, em cinco pontos distintos de cada patamar da área de cultivo formando, assim, amostras compostas. As amostras compostas foram secadas ao ar, homogeneizadas, destorroadas e passadas em peneira de $2 \mathrm{~mm}$ de malha, sendo delas retiradas subamostras para encaminhamento aos Laboratórios de Solos e Resíduos Sólidos do Departamento de Engenharia Agrícola e de Fertilidade e de Física de Solos do Departamento de Solos, da Universidade Federal de Viçosa. Nas análises químicas do solo foram realizadas medições de $\mathrm{pH}$ e condutividade elétrica e a quantificação das concentrações de nitrogênio, amônio, nitrato, $\mathrm{P}$ disponível, concentrações trocáveis de $\mathrm{K}, \mathrm{Ca}, \mathrm{Mg}, \mathrm{Fe}$, $\mathrm{Cu}, \mathrm{Zn}, \mathrm{Mn}, \mathrm{Cd}, \mathrm{Pb}, \mathrm{Ni}, \mathrm{Cr}$, além da determinação, por cálculo, da soma de base trocáveis, índice de saturação por bases, acidez potencial, acidez trocável, conteúdo de matéria orgânica e CTC.

Utilizou-se, na medição da condutividade elétrica, água destilada, na proporção de 1:2,5, valores posteriormente corrigidos para serem expressos como condutividade elétrica no extrato da pasta de saturação do solo; para isto, empregouse a equação $\left(\mathrm{CE}_{\mathrm{es}}=3,696 . \mathrm{CE}_{1: 2,5}\right)$, ajustada para correlacionar os valores obtidos no solo em estudo. Para análise do fósforo disponível lançou-se mão do método colorimétrico (EMBRAPA, 1997). O potássio e o sódio foram quantificados por fotometria de chama enquanto o cálcio e o magnésio o foram por titulometria (APHA, 1995; EMBRAPA, 1997). Os resultados das análises químicas estão apresentados na Tabela 2 .

As análises físicas foram feitas apenas em amostras coletadas na camada de 0-0,20 m e compreenderam a determinação da massa específica do solo e a análise textural (Tabela 3). Realizou-se a análise textural segundo o Método da Pipeta e se obteve a massa específica utilizando-se o método do anel volumétrico (EMBRAPA, 1997). Com base nos resulta- 
Tabela 2. Características químicas iniciais do solo em amostras da área experimental

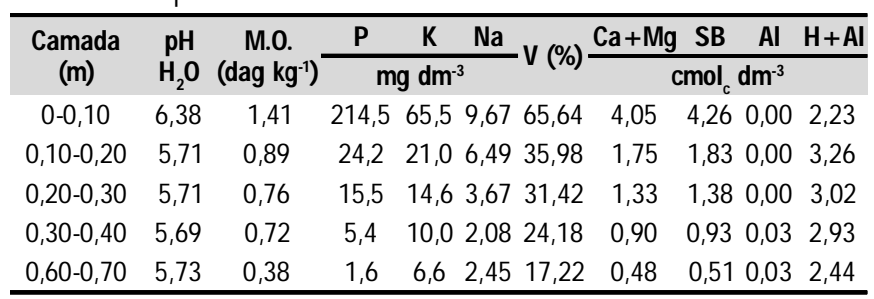

Tabela 3. Distribuição granulométrica e resultado das análises físico-hídricas do solo, em amostras da área experimental, na camada de 0 a $0,20 \mathrm{~m}$

\begin{tabular}{|c|c|c|c|c|}
\hline \multirow{2}{*}{ Camada (m) } & \multicolumn{3}{|c|}{ Distribuição granulométrica $\left(\mathrm{dag} \mathrm{kg}^{1}\right)$} & \multirow{2}{*}{$\begin{array}{c}\text { Massa } \\
\text { específica do } \\
\text { solo }\left(\mathrm{g} \mathrm{cm}^{-3}\right)\end{array}$} \\
\hline & Argila & Silte & Areia & \\
\hline $0-0,20$ & 48 & 8 & 44 & 1,07 \\
\hline
\end{tabular}

dos obtidos verificou-se que a classe textural de enquadramento do solo foi a Argilosa.

No experimento se adotou o delineamento experimental em blocos casualizados, com cinco tratamentos e quatro repetições. $\mathrm{O}$ experimento foi montado com quatro tratamentos $(0$, 250, 500, 750, $1000 \mathrm{~kg} \mathrm{ha}^{-1} \mathrm{~d}^{-1} \mathrm{de} \mathrm{DBO}_{5}$ ), cinco repetições no tempo e cinco profundidades ( 0 a 0,$10 ; 0,10$ a 0,$20 ; 0,20$ a 0,30 ; 0,30 a 0,40 e 0,60 a $0,70 \mathrm{~m}$ ). O tratamento Testemunha foi aquele em o solo das parcelas não foi receptor do percolado (taxa de aplicação zero) tendo recebido apenas água da rede de abastecimento da UFV. A lâmina aplicada diariamente nas parcelas experimentais foi definida com base na Evapotranspiração de Referência (ETo), que foi estimada utilizando-se o método de Penman-Monteith e, para estimativa da lâmina evapotranspirada, utilizou-se o programa Irriplus. Os dados meteorológicos necessários à estimativa da evapotranspiração de referência, como velocidade do vento, umidade relativa do ar, insolação, radiação solar e temperatura, foram obtidos na Estação Meteorológica da Universidade Federal de Viçosa. A precipitação foi medida em pluviômetro instalado na própria área experimental.

Para maior controle da aplicação do percolado de RSU e da água nas parcelas experimentais, empregaram-se regadores manuais e a aplicação de percolado nas parcelas experimentais foi realizada em um período de oito meses. A quantidade de percolado a ser aplicada em cada parcela era calculada antes de cada aplicação, tendo por base as concentrações de $\mathrm{DBO}_{5}$ apresentadas na água residuária a fim de se adequar ao tratamento proposto.

Os dados coletados foram submetidos à análise de regressão. Os modelos de regressão foram escolhidos com base na significância dos coeficientes de regressão, utilizando-se o teste $\mathrm{t}$ em nível de até $15 \%$ de probabilidade, no coeficiente de determinação $\left(\mathrm{R}^{2}\right)$ e no fenômeno em estudo.

Após o início da aplicação do percolado ou água, dependendo do tratamento pré-estabelecido foram retiradas, sempre após cada corte efetuado no capim, amostras de solo em cada parcela experimental, a fim de se investigar prováveis efeitos das aplicações na concentração e na saturação do complexo de troca com sódio. O sódio foi quantificado por fotometria de chama, em alíquotas retiradas do sobrenadante após terem sido as amostras de solo agitadas com o Extrator Mehlich 1 (EMBRAPA, 1997).

O percentual de sódio trocável (PST) e a capacidade de troca catiônica total $\left(\mathrm{CTC}_{\mathrm{T}}\right)$ nas amostras de solo coletadas durante todo o experimento, foram calculados utilizando-se os valores de concentração trocável de $\mathrm{Na}, \mathrm{K}, \mathrm{Ca}+\mathrm{Mg}$, e $\mathrm{H}+\mathrm{Al}$. Para análises dessas variáveis, os mesmos métodos descritos anteriormente também foram utilizados.

O índice PST, indicativo da proporção de sódio adsorvida no complexo de troca de cátions do solo, foi calculado utilizando-se a seguinte equação:

$$
\mathrm{PST}=\frac{\mathrm{Na}}{\mathrm{CTC}_{\mathrm{T}}} \times 100
$$

em que:

$\mathrm{Na}$ - sódio trocável, em $\mathrm{cmol}_{\mathrm{c}} \mathrm{dm}^{-3}$

$\mathrm{CTC}_{\mathrm{T}}$ - capacidade de troca cationnica total do solo, em $\mathrm{cmol}_{\mathrm{c}} \mathrm{dm}^{-3}$

Para verificar os efeitos em médio/longo prazos da aplicação do percolado de RSU em área de solo cultivado com capim-tifton 85 , tendo em vista que em aterros sanitários recéminstalados seria necessária a disponibilização de áreas de aplicação temporária do percolado no solo, até que o aterro disponha de células contendo RSU maduro, obtiveram-se, por simulação, estimativas de como estariam os valores de PST após 3 anos de aplicação do percolado em solo de uma mesma área.

\section{RESULTADOS E DISCUSSÃO}

Apresentam-se, na Tabela 4, as massas de sódio aplicadas mensalmente via percolado de RSU e os valores totais, no solo, conforme o tratamento aplicado.

Tabela 4. Quantidade de sódio ( $\left.\mathrm{kg} \mathrm{ha}^{-1}\right)$ aplicada no período experimental nos diferentes tratamentos (T1) $250 \mathrm{~kg} \mathrm{ha}^{-1} \mathrm{~d}^{-1}$; (T2) $500 \mathrm{~kg} \mathrm{ha}^{-1} \mathrm{~d}^{-1}$; (T3) $750 \mathrm{~kg} \mathrm{ha}^{-1} \mathrm{~d}^{-1}$ e (T4) $1000 \mathrm{~kg} \mathrm{ha}^{-1} \mathrm{~d}^{-1}$ de DBO ${ }_{5}$

\begin{tabular}{ccccc}
\hline Período & \multicolumn{4}{c}{ Na (kg ha-1) } \\
\cline { 2 - 5 } (meses) & T1 & T2 & T3 & T4 \\
$1^{\circ}$ & 848,0 & 1695,9 & 2543,8 & 3391,89 \\
$2^{\circ}$ & 1026,5 & 2052,9 & 3079,4 & 4105,9 \\
$3^{\circ}$ & 679,0 & 1358,0 & 2037,1 & 2716,1 \\
$4^{\circ}$ & 825,1 & 1054,3 & 1581,4 & 2108,5 \\
$5^{\circ}$ & 152,6 & 305,1 & 457,7 & 610,3 \\
Soma & $3.531,1$ & $6.466,35$ & $9.699,4$ & $12.932,5$ \\
\hline
\end{tabular}

Conforme pode ser verificado na Tabela 4 , a taxa de 1000 $\mathrm{kg} \mathrm{ha}^{-1} \mathrm{~d}^{-1}$ de $\mathrm{DBO}_{5}(\mathrm{~T} 4)$, correspondeu à aplicação de 12,93 $\mathrm{t} \mathrm{ha}^{-1}$ de sódio no solo, durante o período de experimentação. Neste cálculo se consideraram o valor total de percolado aplicado, que foi de $418 \mathrm{~m}^{3} \mathrm{ha}^{-1}$, e a concentração de $\mathrm{Na}$ no percolado, que variou de 0,10 a $3,57 \mathrm{~kg} \mathrm{~m}^{-3}$. Embora a quantidade de sódio aplicada tenha sido alta, não houve prejuízo 
durante o período experimental, quanto à produtividade do capim.

Na Figura 2 se apresentam as curvas de concentração de sódio trocável em relação à profundidade do solo. Observase que o tratamento T4, correspondente à maior taxa de aplicação de percolado de RSU, proporcionou maior concentração de sódio no solo, em todas as profundidades estudadas, tendo-se obtido valores tão altos como $170 \mathrm{mg} \mathrm{dm}^{-3}$ na camada de 0-0,10 m. O principal fator para que isto tenha ocorrido foi a adição de sódio proporcionada pela aplicação do percolado do RSU que, conforme mostrado na Tabela 1, é rico neste elemento químico (o sódio pode estar presente em concentrações de até $3.589 \mathrm{mg} \mathrm{L}^{-1}$ em percolado gerado por RSU recém-coletado).

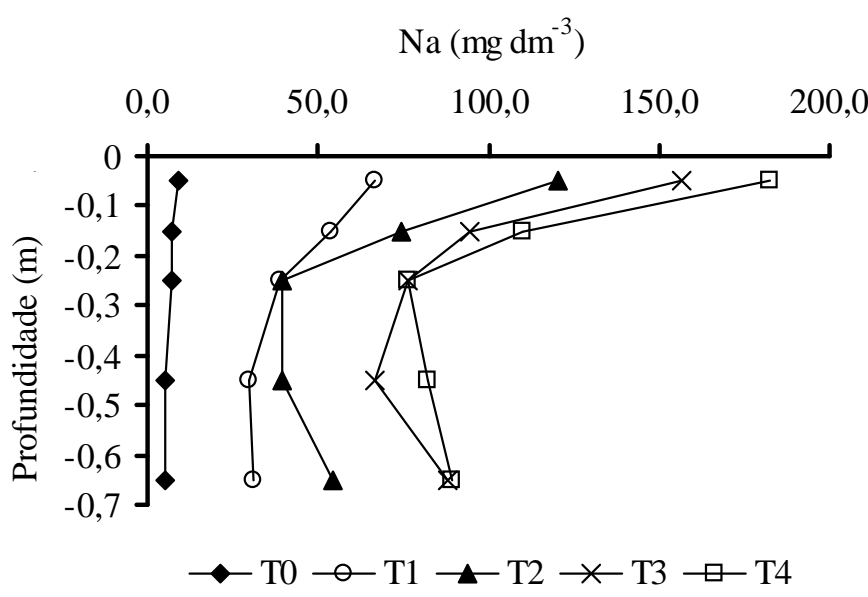

Figura 2. Concentração de sódio trocável no perfil do solo, ao final do período de aplicação de percolado de RSU, em função da profundidade, referente aos tratamentos com água da rede de abastecimento (T0); $250 \mathrm{~kg} \mathrm{ha}^{-1} \mathrm{~d}^{-1}$ (T1); $500 \mathrm{~kg}$ $\mathrm{ha}^{-1} \mathrm{~d}^{-1}$ (T2); $750 \mathrm{~kg} \mathrm{ha}^{-1} \mathrm{~d}^{-1}$ (T3) e $1000 \mathrm{~kg} \mathrm{ha}^{-1} \mathrm{~d}^{-1}$ (T4) de DBO

Queiroz et al. (2004) constataram que a aplicação de água residuária de suinocultura proporcionou acúmulo de sódio trocável atingindo $23,46 \mathrm{mg} \mathrm{dm}^{-3} \mathrm{em}$ solo cultivado com gramíneas forrageiras. Jnad et al. (2001) também observaram aumento na concentração de sódio no solo, decorrente da aplicação de esgoto sanitário tratado via sistema de irrigação por gotejamento superficial, em áreas cultivadas com gramíneas.

Nota-se ainda, na Figura 2, que todos os tratamentos proporcionaram lixiviação do sódio das camadas superficiais para as mais profundas do solo, tendo a concentração de sódio trocável sido maior, em todo o perfil avaliado, que as obtidas no tratamento-testemunha (T0).

Vêem-se, na Figura 3, as equações ajustadas e as curvas de concentração de sódio trocável do solo como função do tempo de aplicação de percolado de RSU para cada taxa de aplicação. Em todas as profundidades avaliadas no solo ( 0 a $0,10 \mathrm{~m} ; 0,10$ a $0,20 \mathrm{~m} ; 0,20$ a $0,30 \mathrm{~m} ; 0,30$ a $0,40 \mathrm{~m}$ e 0,60 a 0,70 $\mathrm{m})$, houve efeito, tanto do tempo de aplicação do percolado RSU como dos tratamentos na concentração de sódio trocável no solo. Verifica-se que as equações ajustadas para todas as camadas do solo e taxas de aplicação apresentaram comportamento linear.

O bom ajuste de equações aos dados obtidos possibilita a utilização na estimativa, em médio e longo prazo, das altera-
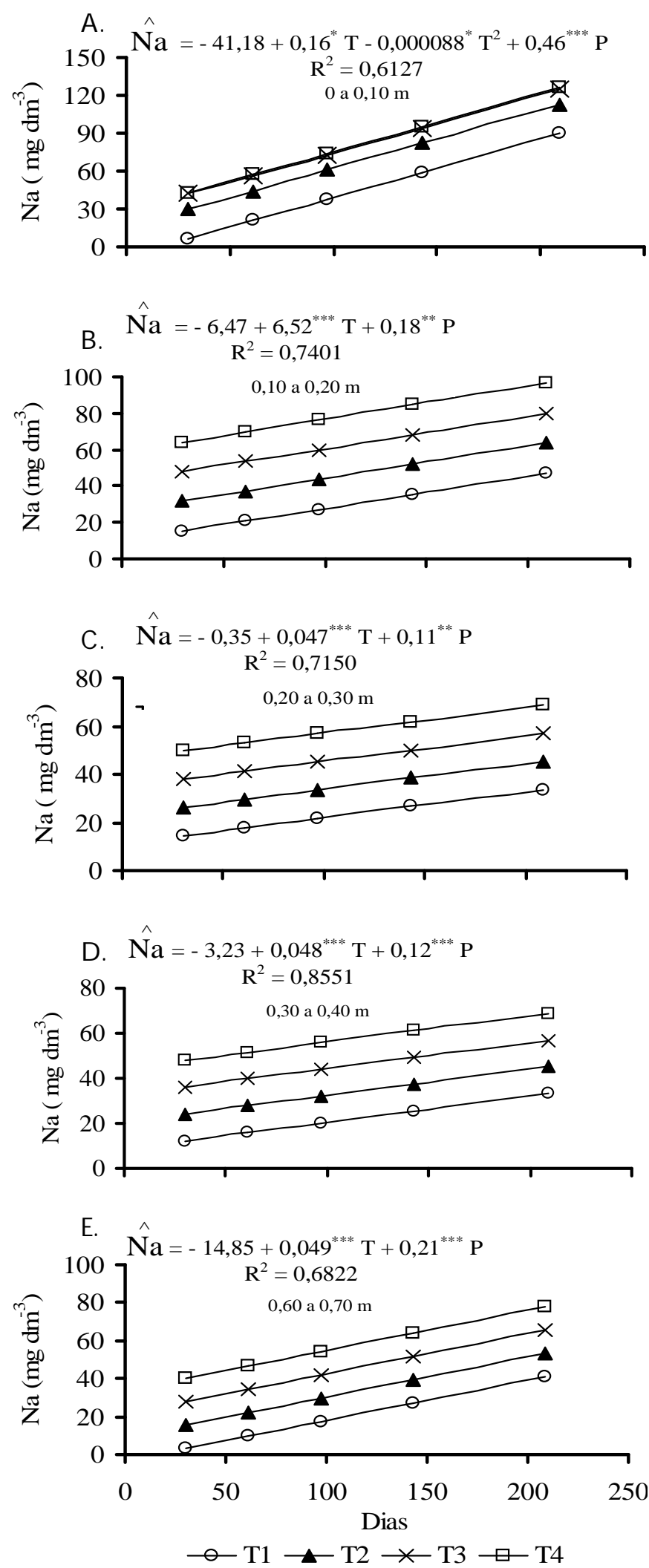

$* * *$, ** e $*$ significativos a 0,$1 ; 1$ e, $5 \%$ de probabilidade, respectivamente, pelo teste $\mathrm{t} ; \mathrm{T}=$ taxa aplicada $\left(\mathrm{kg} \mathrm{ha}^{-1} \mathrm{dia}^{-1}\right) ; \mathrm{P}=$ período de aplicação do percolado (dias)

Figura 3. Estimativa da concentração de sódio trocável nas camadas de 0 a 0,10 $\mathrm{m}($ (A.); 0,10 a $0,20 \mathrm{~m}$ (B. ); 0,20 a 0,30 m (C.); 0,30 a $0,40 \mathrm{~m} ; 0,60$ a $0,70 \mathrm{~m}$ (E.) do solo, durante o período de aplicação (dias) do percolado de RSU, referente aos tratamentos $250 \mathrm{~kg} \mathrm{ha}^{-1} \mathrm{~d}^{-1}$ (T1); $500 \mathrm{~kg} \mathrm{ha}^{-1} \mathrm{~d}^{-1}$ (T2); $750 \mathrm{~kg} \mathrm{ha}^{-1} \mathrm{~d}^{-1}$ (T3) e $1000 \mathrm{~kg} \mathrm{ha}^{-1} \mathrm{~d}^{-1}$ (T4) de DBO 5 
ções nos valores da concentração de sódio trocável no solo, de acordo com a taxa de aplicação do percolado e com a profundidade.

$\mathrm{Na}$ Tabela 5 se apresentam os valores percentuais de sódio trocável (PST) obtidos por ocasião da finalização da aplicação de percolado de RSU nas parcelas experimentais, nos diferentes tratamentos e profundidades do solo, tomando-se a $\mathrm{CTC}_{\mathrm{T}}$, obtida inicialmente no solo, como referência.

Tabela 5. Percentual de sódio trocável (PST), ao final do período de aplicação de percolado de resíduo sólido urbano (RSU) no solo, em que T1, T2, T3 e T4 se referem, respectivamente, à aplicação de 250, 500, 750 e $1000 \mathrm{~kg} \mathrm{ha}^{-1} \mathrm{~d}^{-1}$ de $\mathrm{DBO}_{5}$

\begin{tabular}{ccccc}
\hline \multicolumn{5}{c}{ PST (\%) } \\
\hline Profundidade (m) & T1 & T2 & T3 & T4 \\
$-0,05$ & 4,45 & 8,04 & 10,50 & 12,23 \\
$-0,15$ & 4,58 & 6,35 & 8,05 & 9,40 \\
$-0,25$ & 3,82 & 3,92 & 7,54 & 7,54 \\
$-0,45$ & 3,35 & 4,47 & 7,48 & 9,27 \\
$-0,65$ & 4,54 & 8,05 & 13,02 & 13,17 \\
\hline
\end{tabular}

Analisando-se os dados apresentados na Tabela 5 verifica-se que, ao final do período de realização do experimento (após oito meses de aplicação de percolado de RSU nas parcelas experimentais), os valores de PST permaneceram abaixo do limite de $15 \%$, considerado indicador de sodicidade do solo (Richards, 1997), não tendo sido atingido, portanto, até este momento, alto nível de salinização/sodificação no solo de nenhuma das parcelas experimentais. A concentração de sódio trocável no perfil se manteve em níveis considerados aceitáveis para que não seja colocada em risco a qualidade do solo, no que se refere ao problema de salinização/sodificação e, consequentemente, risco potencial, também, para as águas subterrâneas.

Torna-se oportuno que a prática de aplicação de percolado de RSU seja ambientalmente sustentável, considerandose um período de aplicação maior, tendo em vista que, em períodos maiores de tempo, altos níveis de contaminação poderão ser alcançados nas áreas de aplicação temporária de percolado, em aterros sanitários novos, razão porque valores de PST no solo foram estimados utilizando-se as equações ajustadas para concentração de Na trocável no solo (Figura 2); isto foi feito para que se pudesse calcular qual seria o período máximo de aplicação a fim de que não houvesse superação do índice de $15 \%$ na saturação do complexo de troca $\left(\mathrm{CTC}_{\mathrm{T}}\right.$ inicial) com sódio, considerando-se constante a concentração de sódio no percolado aplicado $\left(99,1 \mathrm{mg} \mathrm{L}^{-1}\right)$. O tempo máximo calculado foi de 1,2 anos de aplicação ininterrupta em solos das parcelas experimentais submetidas aos tratamentos T1, T2, T3 e T4, Cambissolo Háplico Tb distrófico latossólico, para que a percentagem de saturação de sódio alcançasse $15 \%$ na camada mais superficial do solo (0$0,10 \mathrm{~m})$, conforme apresentado na Tabela 6 .

Esses resultados podem ser considerados indicativos de que a aplicação da maior taxa avaliada (1000 $\mathrm{kg} \mathrm{ha}^{-1} \mathrm{~d}^{-1} \mathrm{de}$ $\mathrm{DBO}_{5}$ ) pode ser tida como referência superior quando se quer minimizar riscos relativos à qualidade do solo e das águas
Tabela 6. Percentual de sódio trocável (PST), para 1,2 anos de aplicação ininterrupta de percolado de resíduo sólido urbano (RSU), em que T1, T2, T3 e T4 se referem, respectivamente, às taxas de $250,500,750$ e $1000 \mathrm{~kg} \mathrm{ha}^{-1} \mathrm{~d}^{-1}$ de $\mathrm{DBO}_{5}$

\begin{tabular}{ccccc}
\hline \multicolumn{5}{c}{ PST (\%) } \\
\hline Profundidade (m) & T1 & T2 & T3 & T4 \\
$-0,05$ & 12,7 & 14,1 & 14,9 & 15,0 \\
\hline
\end{tabular}

subterrâneas. Em uma estimativa de como estaria a situação do solo considerando-se o período de 3 anos de aplicação ininterrupta, obtiveram-se os dados apresentados na Tabela 7.

Verifica-se, com base nos valores apresentados na Tabela 7 que, em todos os tratamentos, o limiar de sodicidade do solo foi superado na camada mais superficial $(0$ a $0,10 \mathrm{~m})$ e na mais profunda $(0,60$ a $0,70 \mathrm{~m})$, o que pode ser considerado fator limitante para esta disposição do percolado de RSU no solo; entretanto, visto que a concentração de sódio no percolado decresce com a idade do RSU e que a partir do $3^{\circ}$ ano de aplicação a área não deverá mais receber percolado de RSU, espera-se rápida recuperação do solo quando a precipitação local for condizente com a de climas com estação chuvosa definida, como ocorre em grande parte do Brasil; ainda assim, se for considerado necessário se resguardar em $15 \%$ o valor máximo de proporção de sódio no complexo de troca do solo, o que pode ser reconhecido como adequado para áreas fora dos limites do aterro sanitário ou de áreas do aterro onde não haverá disposição de RSU, pode-se pensar em troca de área de aplicação ininterrupta do percolado de RSU, a cada 1,2 anos.

Com base nos resultados obtidos de PST, em uma estimativa de ocorrência no período de 3 anos (tempo suficiente para envelhecimento do RSU no aterro sanitário, tornando as células potenciais receptoras do percolado, em sistema de recirculação) de aplicação do percolado de RSU no solo, não se pode dizer que tenha havido maior impacto de uma taxa que a outra; entretanto e se considerando que, a partir da taxa de $500 \mathrm{~kg} \mathrm{ha}^{-1} \mathrm{~d}^{-1}$ de $\mathrm{DBO}_{5}$, ocorre aumento expressivo na concentração de Na trocável também nas camadas mais profundas do solo (Figura 2), indicando claro risco de contaminação de águas subterrâneas, recomenda-se, neste caso, que se utilize a referida taxa como de aplicação máxima. Caso a área de disposição seja interna ao aterro e disponha de sistema de captação de percolados, tal como ocorre nas áreas

Tabela 7. Percentual de sódio trocável no solo, estimado considerando-se uma aplicação ininterrupta de percolado de resíduo sólido urbano (RSU) durante de três anos, em que T1, T2, T3 e T4 se referem, respectivamente, às taxas de 250,500, 750 e $1000 \mathrm{~kg} \mathrm{ha}^{-1} \mathrm{dia}^{-1}$ de $\mathrm{DBO}_{5}$

\begin{tabular}{ccccc}
\hline \multicolumn{5}{c}{ 3 anos } \\
\hline Profundidade (m) & T1 & T2 & T3 & T4 \\
$-0,05$ & 20,4 & 21,4 & 21,9 & 21,9 \\
$-0,15$ & 13,1 & 14,1 & 15,1 & 16,2 \\
$-0,25$ & 9,3 & 10,1 & 11,0 & 11,8 \\
$-0,45$ & 13,5 & 14,6 & 15,8 & 16,9 \\
$-0,65$ & 22,9 & 24,2 & 25,4 & 26,7 \\
\hline
\end{tabular}


preparadas para formação das células de RSU no aterro, considera-se que taxas tão altas como as de $1000 \mathrm{~kg} \mathrm{ha}^{-1} \mathrm{~d}^{-1} \mathrm{de}$ $\mathrm{DBO}_{5}$ poderão ser usadas sem risco ambiental.

\section{CONCLUSÕES}

1. A aplicação do percolado de RSU proporcionou significativa alteração nos valores de $\mathrm{Na}$ do solo, tendo ocorrido seu acúmulo em todas as camadas estudadas, embora isto não tenha causado prejuízo à produtividade do capim-tifton 85.

2. Taxas de aplicação inferiores a $500 \mathrm{~kg} \mathrm{ha}^{-1} \mathrm{~d}^{-1} \mathrm{de} \mathrm{DBO}_{5}$ de percolado de RSU não deverão proporcionar problemas ao solo nem à água subterrânea, mesmo que aplicada em áreas que não serão utilizadas para disposição de RSU. Em áreas internas do aterro sanitário e que serão receptoras de RSU, essas taxas podem ser tão altas como $1000 \mathrm{~kg} \mathrm{ha}^{-1} \mathrm{~d}^{-1} \mathrm{de}$ $\mathrm{DBO}_{5}$.

3. O período máximo de aplicação de percolado de RSU no solo de forma a não se superar o PST de 15\%, é de 1,2 anos, aplicando-se uma taxa de até $1000 \mathrm{~kg} \mathrm{ha}^{-1} \mathrm{~d}^{-1} \mathrm{de}^{\mathrm{DBO}_{5}}$.

\section{LITERATURA CITADA}

Aluko, O. O.; Sridhar, M. K. C. Application of constructed wetlands to the treatment of leachates from a municipal solid waste landfill in Ibadan, Nigéria. Journal of Environmental Health, v.80, n.10, p.58-62, 2005.

APHA - American Public Health Aassociation. Standard methods for the examination of water and wastewater. 19.ed. New York: APHA, WWWA, WPCR, 2005. s.n.p.

Carvalho, A. L.; Matos, A. T. de; Hamakawa, P. J.; Azevedo R. F. Produção de percolado por resíduos sólidos urbanos de diferentes idades, na presença de resíduos da construção civil e sob recirculação. Engenharia na Agricultura, v.14, n.2, p.131138, 2006.

CETESB - Companhia de Tecnologia de Saneamento Ambiental e Limpeza Pública-Caracterização e estudo de tratabilidade de líquidos percolados de aterros sanitários. São Paulo: CETESB, 1995. 66p.
EMBRAPA - Empresa Brasileira de Pesquisa Agropecuária - Centro Nacional de Pesquisa de Solos. Manual de métodos de análise de solo. 2.ed. Rio de Janeiro: EMBRAPA, 1997. 212p. Documento 1.

IPT/CEMPRE - Instituto de Pesquisa Tecnológicas - Compromisso Empresarial para Reciclagem -. Lixo municipal. Manual de gerenciamento integrado. 2.ed. São Paulo: CEMPRE, 2000. $370 \mathrm{p}$.

Jnad, I.; Lesikar, B.; Kenimer, A.; Sabragh, G. Subsurface drip dispersal of residential effluent: I. Soil Chemical Characteristics. Transactions of the ASAE, v.44, n.5, p.1152-1158, 2001.

Kempers, A. J.; Zweers, A. Ammonium determination in soil extracts by the salicylate method. Soil Science Plant Analyze, v.17, n.7, p.715-723, 1986.

Marnie, L. W.; Bitton, G.; Townsend, T. Heavy metal binding capacity (HMBC) of municipal solid waste landfill leachates. Chemosphere, v.60, n.2, p.206-215, 2005.

Matos, A. T. de; Carvalho, A. L. de; Azevedo, I. C. D. d'A. Viabilidade do aproveitamento agrícola de percolados de resíduos sólidos urbanos, Revista Brasileira de Engenharia Agrícola e Ambiental, v.12, n.4, p.435-440, 2008.

Oliveira, F. C.; Matiazzo, M. E.; Marciano, C. R.; Rosseto, R. Efeitos de aplicações sucessivas de lodo de esgoto em Latossolo Amarelo distrófico cultivado com cana-de-açúcar: carbono orgânico, condutividade elétrica, $\mathrm{pH}$ e CTC. Revista Brasileira de Ciência do Solo, v.26, n.3, p.505-519, 2002.

Qian, X.; Koerner, R. M.; Gray, D. H. Geotechnical aspects of landfill design and construction. Upper Saddle River: Prentice Hall, 2002. 717p.

Queiroz, F. M. de; Matos, A. T. de; Pereira, O. G.; Oliveira, R. A. de. Características químicas do solo submetido ao tratamento com esterco líquido de suínos e cultivado com gramíneas forrageiras. Ciência Rural, v.34, n.5, p.1487-1492, 2004.

Richards, L. A. Diagnóstico y rehabilitacion de suelos salinos e sódico. México: Editorial Limusa, 1997. 172p.

Vieira, E. O. Índice de lixiviação e modelagem do transporte de pesticidas no solo. Viçosa: UFV. 2003. 184p. Tese Doutorado

Yang, J. E.; Skogley, E. O.; Schaff, B. E.; Kim, J. J. A simple spectrophotometric determination of nitrate in water, resin and soil extracts. Journal of American Soil Society. v.62, p.1108-1115, 1998. 